\title{
Aplikasi Smartphone Untuk Anti Bully
}

\author{
Agung A. Pramudji ${ }^{1}$; Benaya Oktavianus ${ }^{2}$; Randy Dwi ${ }^{3}$; Vania Margarita ${ }^{4}$; \\ Harco Leslie Hendric Spits Warnars ${ }^{5}$ \\ ${ }^{1,2,3}$ Departemen Sistem Informasi, Sekolah Sistem Informasi, Universitas Bina Nusantara, Jakarta, \\ Indonesia 11480 \\ 4, 5 Departemen Ilmu Komputer, Peminatan Doktor Ilmu Komputer, Universitas Bina Nusantara, \\ Jakarta, Indonesia 11480 \\ ${ }^{1}$ agung.pramudji@binus.ac.id \\ ${ }^{2}$ benaya.oktavianus@binus.ac.id \\ 3randy.dwi@binus.ac.id \\ ${ }^{4}$ vania.margarita@binus.ac.id \\ ${ }^{5}$ spits.hendric@binus.ac.id
}

\begin{abstract}
Bullying is aggressive activities not only among school aged children but it can be happened in higher education, office or even in family on daily basis. Bullying involves physical and non physical action which is repeated acted and can be represented in verbal, social and physical thing. Bullying has negative for both perpetrators and victims, the perpetrators will have bad habit which can influence the way their living in the future and particularly for victim it will make them become alone and not open to surrounding relationships.In this paper, we proposed an application which can help to reduce the negative effect of bullying by reporting any bullying happened and do the next action based on meeting result. Moreover, this application will give open private consultation for both perpetrators and victims in order to reduce bullying activities and recognized as bullying. Creating forum for both community who are interested to reduce bullying negatve effect and provide information regarding with negative effect of bullying will help people to educate themselves regarding with bullying.
\end{abstract}

Keywords: Anti Bully application, IT for Anti Bully, physiatrist Computer Science

\begin{abstract}
ABSTRAK
Bullying adalah kegiatan agresif tidak hanya di antara anak-anak usia sekolah tetapi dapat terjadi di pendidikan tinggi, kantor atau bahkan dalam keluarga setiap hari. Bullying melibatkan tindakan fisik dan non fisik yang diulangi dan dapat diwakili dalam hal verbal, sosial dan fisik. Bullying berdampak negatif bagi pelaku dan korban, pelaku akan memiliki kebiasaan buruk yang dapat mempengaruhi cara hidup mereka di masa depan dan khususnya bagi korban akan membuat mereka menjadi sendirian dan tidak terbuka untuk hubungan di sekitarnya. Dalam makalah ini, kami mengusulkan aplikasi yang dapat membantu mengurangi efek negatif dari intimidasi dengan melaporkan setiap intimidasi yang terjadi dan melakukan tindakan selanjutnya berdasarkan hasil pertemuan. Selain itu, aplikasi ini akan memberikan konsultasi pribadi terbuka untuk pelaku dan korban untuk mengurangi kegiatan intimidasi dan diakui sebagai intimidasi. Membuat forum untuk kedua komunitas yang tertarik untuk mengurangi efek negatif bullying dan memberikan informasi mengenai efek negatif bullying akan membantu orang untuk mendidik diri mereka sendiri mengenai bullying.
\end{abstract}

Kata kunci: Aplikasi untuk anti bully, Teknologi informasi untuk anti bully, Ilmu Komputer Fisiatris 


\section{PENDAHULUAN}

Dalam beberapa tahun terakhir, kata "bullying" semakin sering terdengar di Indonesia. Bullying telah terjadi sejak lama, tetapi Namanya menjadi lebih popular sejak bullying di Indonesia telah meningkat dan telah terjadi di segala usia. Ada beberapa jenis bullying, seperti:

1. Penindasan Fisik

Penindasan fisik, tanda-tanda yang menjadi korban penindasan fisik akan menerima berbagai perlakuan fisik yang kejam, mulai dari menghalangi jalan korban, menyandung korban, mendorong, memukul, menahan, sampai melempar barang kea rah korban.

2. Penindasan Verbal

Penindasan verbal dilakukan dengan kata-kata, pernyataan, nama panggilan, dan tekanan psikologis yang menyakitkan atau juga yang merendahkan korban.

3. Pengucilan

Korban yang dikucilkan biasanya tidak mengalami penindasan secara fisik maupun verbal, yang terjadi adalah korban yang diabaikan dan dimusuhi oleh lingkungan sosial mereka. Korban menjadi merasa terisolasi, dipaksa untuk menyendiri, dan akan merasa sulit untuk menemukan teman. Karena biasanya, pelaku bullying memiliki pengaruh yang cukup kuat untuk membujuk dan mengajak orang lain untuk mengisolasi korban.

4. Penindasan dalam Dunia Maya

Biasanya lebih dikenal sebagai vyber-bullying, adalah penindasan yang bias dianggap baru. Penindasan ini terjadi di dunia maya, contohnya melalui aplikasi media social dan chatting. Karena sifatnya yang bebas, korban dapat menerima penindasan dari seseorang yang tidak dikenalnya atau seseorang yang menyamarkan nama penggunanya. Penindasan yang terjadi biasanya dalam bentuk penghinaan atau sindiran. Bisa juga dengan menyebarkan rumor atau berita tidak benar tentang korban yang disebarkan melalui media social.

5. Penincasan Seksual

Penindas biasanya memberi komentar, menggoda, mengintip, bahkan menyentuh korban secara seksual. Tidak hanya itu, penindasan secara seksual uga mencakup penyebaran fotofoto korban secara diam-diam untuk memuaskan gairah seksual para pelaku, atau memaksa korban untuk menonton atau melihat hal-hal porno [1].

Berdasarkan data dari KPAI atau Komisi Perlindungan Anak Indonesia pada tahun 2017, Ada 73 kasus bullying yang terjadi pada anak-anak yang berusia 12 hingga 17 tahun. Pada 2018, KPAI mengatakan bahwa peningkatan intimidasi di media sosial adalah 112 kasus [2].

Perilaku bully memiliki banyak efek yang negatif terhadap korban; beberapa contoh efek dari bullying adalah:

a. Memiliki kelainan mental:

- Depresi

- Rendah diri

- Gelisah

- Sulit tidur nyenyak

- Ingin melukai diri sendiri

b. Perubahan yang terlihat jelas pada korban bullying:

- Tidak antusias untuk pergi ke sekolah

- Prestasi belajar jadi menurun

- Nafsu makan menurun

- Kabur dari rumah 
- Terlihat stress saat pulang ke rumah

- Ada luka pada tubuh korban

Tindakan bully sangat menggangu bagi banyak orang, dan terkadang hal-hal yang tidak pantas untuk korban pun terjadi. Bullying juga menyebabkan kerusakan di masa depan, yang menyakiti korban dan juga orang-orang di sekitarnya. Orang yang suka mem-bully juga harus diberi efek jera, sehingga ia tidak mengulangi tindakannya, karena jika diizinkan, ia akan menjadi orang yang tidak pantas untuk orang-orang di sekitarnya, seperti teman dan keluarga.

Karena kasus-kasus bullying yang merajalela, kami mencoba membuat aplikasi berbasis mobile untuk membantu para korban bullying mendapatkan bantuan psikologis, dari psikiater yang telah kami sediakan dan bekerja sama dengan Asosiasi Psikiater Indonesia (HIMPSI) untuk membantu menyelesaikan masalah bullying di masyarakat dengan konsultasi online dalam aplikasi, dan juga kerahasiaan dijamin. Selain itu, kami akan menghubungkan aplikasi yang kami buat, untuk dapat terhubung ke kontor polisi setempat untuk membantu korban dalam pelaporan kepada pihak berwajib, jika merea ingin diproses secara hukum, dengan melaporkan kepada pihak berwenang untuk membantu menciptakan efek jera pada pelaku bullying. Alasan kami membuat aplikasi ini adalah menjadi dampak bagi banyak orang dan mencoba memajukan negara dari membuat perubahan kecil pada generasi muda. Jika bullying dibiarkan berlanjut tanpa respon yang keras untuk menghentikannya, mungkin generasi muda kita akan menjadi malu dan tidak mampu melakukan perubahan yang lebih baik. Kami berharap bahwa dari aplikasi yang dianggap kecil dan tidak berguna oleh banyak orang ini, dapat memiliki dampak yang signifikan pada korban bullying yang membutuhkannya, untuk mendengarkan cerita mereka.

\section{TINJAUAN PENELITIAN SEBELUMNYA}

Sebelum kami membuat makalah ini, kami mempelajari beberapa makalah penelitian yang sudah ada sebelumnya, dimana makalah tersebut berasal dari makalah nasional maupun internasional, yang sebagian besar sebagai makalah akademis seperti jurnal atau konfrensi internasional.

Menurut penelitian, di jaman sekarang ini, anak muda sangat rentan terhadap masalah emosional. Gangguan tersebut dapat muncul dalam berbagai macam, misalnya, gangguan depresi dan kecemasan. Ini disebabkan karena berbagai alasan, baik pengaruh genetik, penyakit, dan lingkungan [3]. Bahkan di lingkungan sekolah, masih ada banyak kasus bullying. Di mana sekolah seharusnya menjadi tempat untuk belajar dan membentuk karakter seseorang, menjadi tempat yang mengerikan bagi sebagian orang [4]. Sebagian besar pelaku dapat melakukan hal-hal seperti itu karena kurangnya pendidikan moral dari lingkungan keluarga. Komunikasi dalam keluarga sangat penting dalam mencegah bullying. Menurut penelitian, mereka mempelajari perilaku korban bully dan komunikasi antara keluarga. Ternyata peran keluarga sangat penting dalam kasus bullying [5]. Menurut data yang ada, terdapat $23 \%$ anak muda di-bully melalui internet, sementara ada $16 \%$ anak muda yang menjadi pelaku cyberbullying.

Selain itu, 61\% kasus bullying sisanya terjadi secara langsung baik di lingkungan sekolah dan di masyarakat [6]. Oleh karena itu, korban bully menjadi depresi, cenderung pendiam dan tidak percaya diri. Untuk korban yang mengalami penindasan secara verbal, tingkat depresi mereka lebih tinggi daripada korban yang ditindas secara tidak langsung. Karena intimidasi verbal dilakukan langsung kepada korban sementara cyberbullying dilakukan melalui media sosial atau internet [7]. Menurut penelitian, dampak dari pelaku bullying secara verbal sangat mengerikan. Korban dapat mengalami trauma, depresi berat, menjadi pendiam, tidak percaya diri, dan efek terburuknya adalah 
bunuh diri. Meskipun hanya mengejek atau menyebarkan rumor, itu dapat dihitung sebagai bullying tidak langsung yang menyebabkan korban menjadi stres dan tertekan [8].

Penelitian menunjukkan bahwa pelaku bullying dapat ditebak melalui karakter pribadi, masalah keluarga, dan masalah kesehatan mental. Karena itu, pendidikan moral sangat penting untuk diajarkan di masa kecil. Jadi, dibutuhkan kemauan serta kesadaran dari orang tua dan orang-orang di sekitarnya untuk mengajarkan dan memberikan contoh yang baik [9]. Sekolah juga diharapkan memperhatikan siswa-siswanya. Mengamati siswa mereka, jika ada siswa yang memiliki masalah mental atau siswa yang diganggu. Sehingga mereka dapat dengan segera dibantu oleh para profesional [10], dalam mengamati siswa, dapat dilihat melalui karakteristik berikut. Biasanya, korban cenderung pendiam, gelisah, tidak nyaman, dan dikucilkan dari masyarakat. Mereka tidak terlalu percaya diri, selalu melihat hal-hal negatif yang ada di dalamnya. Menganggap diri mereka yang paling bodoh atau gagal [11].

Bullying memiliki efek buruk untuk waktu yang lama. Orang yang menjadi korban bullying dapat berubah menjadi pelaku karena stres berat, depresi, dan trauma [12] [13]. Menurut data, sebagian besar pelaku bullying secara langsung adalah anak laki-laki. Mereka lebih terlibat dalam intimidasi verbal atau fisik, sementara pelaku perempuan lebih banyak terlibat dalam intimidasi tidak langsung dan cyberbullying, misalnya, seperti menghina dan menyebarkan rumor yang membuat korban malu [14]. Kami menemukan bahwa cyberbully di sekolah sering terjadi. Para pelaku biasanya tidak sadar bahwa perilakunya termasuk dianggap sebagai bullying. Siswa yang menjadi korban biasanya menjadi takut dan malu untuk pergi ke sekolah. [15]

Sejauh ini, ada banyak program anti- bullying yang dijalankan di sekolah. Diharapkan bahwa dengan adanya program anti-bullying ini dapat mengurangi insiden bullying di sekolah [16]. Dalam program ini, diajarkan untuk memahami konsep bullying, di mana bulling merupakan peristiwa kehidupan yang penuh tekanan [17]. Menurut penelitian, sebagian besar pelaku bullying di sekolah adalah korban bullying di jalanan. Ini cenderung membuat mereka ingin mendominasi wilayah sekolah dengan mengintimidasi siswa lain [18]. Oleh sebab itu, peran lingkungan sosial menjadi penting, terutama bagi kaum remaja, yang biasanya masih mencari jati diri mereka. Menurut data (Holt, Espelage, 2007), mereka melakukan penelitian terhadap 784 anak muda, pendapat mereka tentang kasus-kasus bullying. Ditemukan bahwa 61,6\% anak muda tidak pernah terlibat dalam bullying, 14,3\% adalah pelaku, 12,5\% adalah korban, dan 11,6\% adalah korban bully. Membuktikan bahwa masih ada anak muda yang memiliki karakter baik dan tidak ingin terlibat dalam bullying [19].

Selain di sekolah, bullying juga terjadi di tempat kerja, yang mengakibatkan para korban menjadi tidak nyaman di tempat kerja. Perilaku ini memiliki dampak yang parah bagi individu dan perusahaan, tetapi sayangnya banyak pemimpin perusahaan tidak mengetahui insiden bullying ini. Pendekatan yang tepat diperlukan untuk menangani insiden-insiden seperti ini [20]. Cyberbullying juga terjadi dalam suatu hubungan. Biasanya, dalam masalah hubungan seperti putus, iri, dan cemburu [21]. Oleh karena itu, tindakan bullying yang dilakukan oleh pelaku perlu diperhatikan, didiskusikan dan dipertimbangkan hukumannya. Agar tidak ada lagi perilaku bullying yang membuat orang lain tertekan dengan kehidupannya [22].

\section{USULAN APLIKASI UNTUK ANTI BULLY}

Aplikasi mobile yang akan kami usulkan dibuat untuk korban bully agar mereka dapat berkonsultasi tentang kejadian yang mereka alami. Kami sangat berharap bahwa hal ini dapat mengurangi tingkat depresi atau trauma yang korban alami. Aplikasi ini bernama Protect ur Smile dengan tagline "Be Happy Now." Aplikasi kami merupakan mobile-friendly. 
Gambar 1. Menunjukan use case aplikasi mobile yang kami ajukan dimana pengguna dapat mendaftar, login, membuat laporan bully, berkonsultasi dengan psikiater, membuat post di forum dan mengakses informasi lain. Di sisi lain, Admin dapat melihat laporan yang pengguna laporkan dan menindaklanjutinya dengan melaporkan ke pihak yang bertanggung jawab, membuat dan menyunting forum dan membuat konten di menu informasi. Class Diagram aplikasi mobile kami yang berisi atribut dari setiap class dapat dilihat di gambar 2. Menu utama aplikasi mobile dapat dilihat di gambar 3.

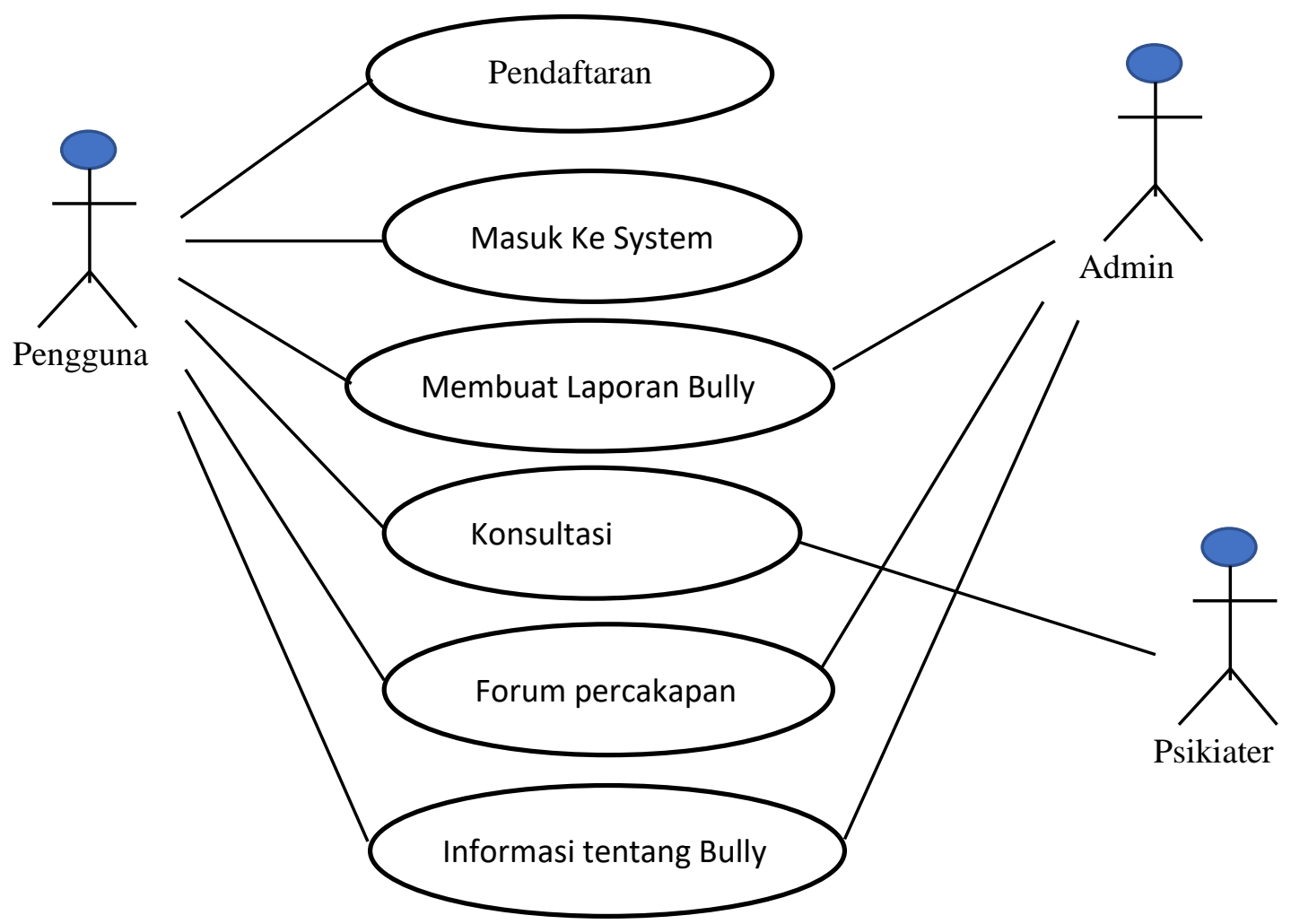

Gambar 1. Use Case Diagram model desain untuk aplikasi anti-bully

Use Case Diagram aplikasi mobile yang kami usulkan yang dapat dilihat pada gambar 1 menunjukkan beberapa aktivitas dan fitur seperti:

1. Pendaftaran

Digunakan untuk para pengguna baru yang ingin menggunakan aplikasi mobile ini. Di halaman ini, mereka harus mengisi data diri mereka seperti nama, email, kata sandi dan konfirmasi kata sandi seperti yang dapat dilihat pada gambar 4 (a).

2. Masuk Ke system

Halaman login digunakan untuk pengguna yang terdaftar untuk membuka aplikasi mobile ini. Di halaman ini, mereka hanya perlu mengisi email dan kata sandi terdaftar seperti yang dapat dilihat pada gambar 4(b).

3. Membuat laporan bully

Halaman ini digunakan untuk pengguna yang ingin melaporkan tindak bully yang mereka alami atau orang lain. Mereka dapat menambahkan bukti-bukti seperti foto yang dapat dilihat pada gambar 5 (a). Format file yang didukung untuk mengirimkan bukti antara lain jpg, pdf, mp4, mp3, gif dan png. Admin juga dapat mengakses halaman ini untuk melihat laporan dan menindaklanjutinya. 
4. Konsultasi

Halaman ini digunakan pengguna untuk berkonsultasi dengan psikiater kami. Konsultasi dilakukan melalui pesan teks seperti digambar 5 (b). pengguna dapat memilih untuk menampilkan nama mereka atau tetap sebagai anonim sehingga mereka tidak akan merasa takut dan malu karena privasinya terungkap.

5. Forum Percakapan

Halaman ini digunakan pengguna untuk berinteraksi dengan pengguna lain seperti yang bisa dilihat di gambar 6. Mereka bisa membuat dan mengomentari post di forum diskusi.

6. Informasi tentang Bully

Halaman ini menampilkan profi pengguna yang dapat dilihat di gambar 7(a) dan profil psikiater di gambar 7(b). pengguna dapat melihat latar belakang pendidikan dan karir psikiater. Lalu ada juga berbagai informasi tentang bully. Contohnya seperti peraturan tentang bully di Indonesia (dapat dilihat pada gambar 8) pelaku bullying terhadap anakanak dapat dihukum berdasarkan UU No. 23 tahun 2002 yang mengatur tentang perlindungan anak. Jika ada pelaku bully disekolah, kita bisa menggunakan pasal 54 dalam UU 35/2004. UU tersebut berisikan bahwa anak-anak di dalam lingkungan pendidikan diharuskan menerima perlindungan dari tindakan fisik, mental, dll [23].

Aplikasi mobile kami memiliki tujuh tabel database antara lain Survivor, Report, Forum, Admin, Consultation, Psychiatrist dan ReportDetail yang dapat dilihat pada gambar 2. Tabel Survivor mempunya delapan atribut dan tujuan tabel ini adalah untuk menyimpan data pengguna. Table ini terhubung dengan 3 tabel lainnya, yaitu Consultation, Report dan Forum. Hubungan antara tabel konsultasi dan survivor adalah $1 \ldots *$ ke 1 karena 1 survivor bias membuat 1 atau lebih konsultasi. Sama dengan tabel survivor dan tabel forum karena 1 survivor dapat melakukan 1 atau banyak post forum. Tabel report digunakan untuk menyimpan deskripsi dan bukti pendukung. Hubungan tabel survivor dan tabel report adalah 1 ke $1 .{ }^{*}$ karena 1 survivor dapat membuat 1 atau banyak laporan. Tabel Consultation digunakan untuk menyimpan konsultasi antara user dan psikiater. Tabel ini terhubung dengan tabel Psychiatrist. Seorang psikiater dapat menangani 1 atau lebih konsultasi. Tabel forum digunakan untuk menyimpan informasi tentang berita, acara dan diskusi. Tabel ini terhubung dngan tabel Admin karena seorang admin dapat menangani 1 atau lebih post pada forum. Tabel admin digunakan untuk menyimpan data admin. Tabel admin juga terhubung dengan reportDetail karena admin dapat melihat dan menindaklanjuti laporan yang telah diterima. 


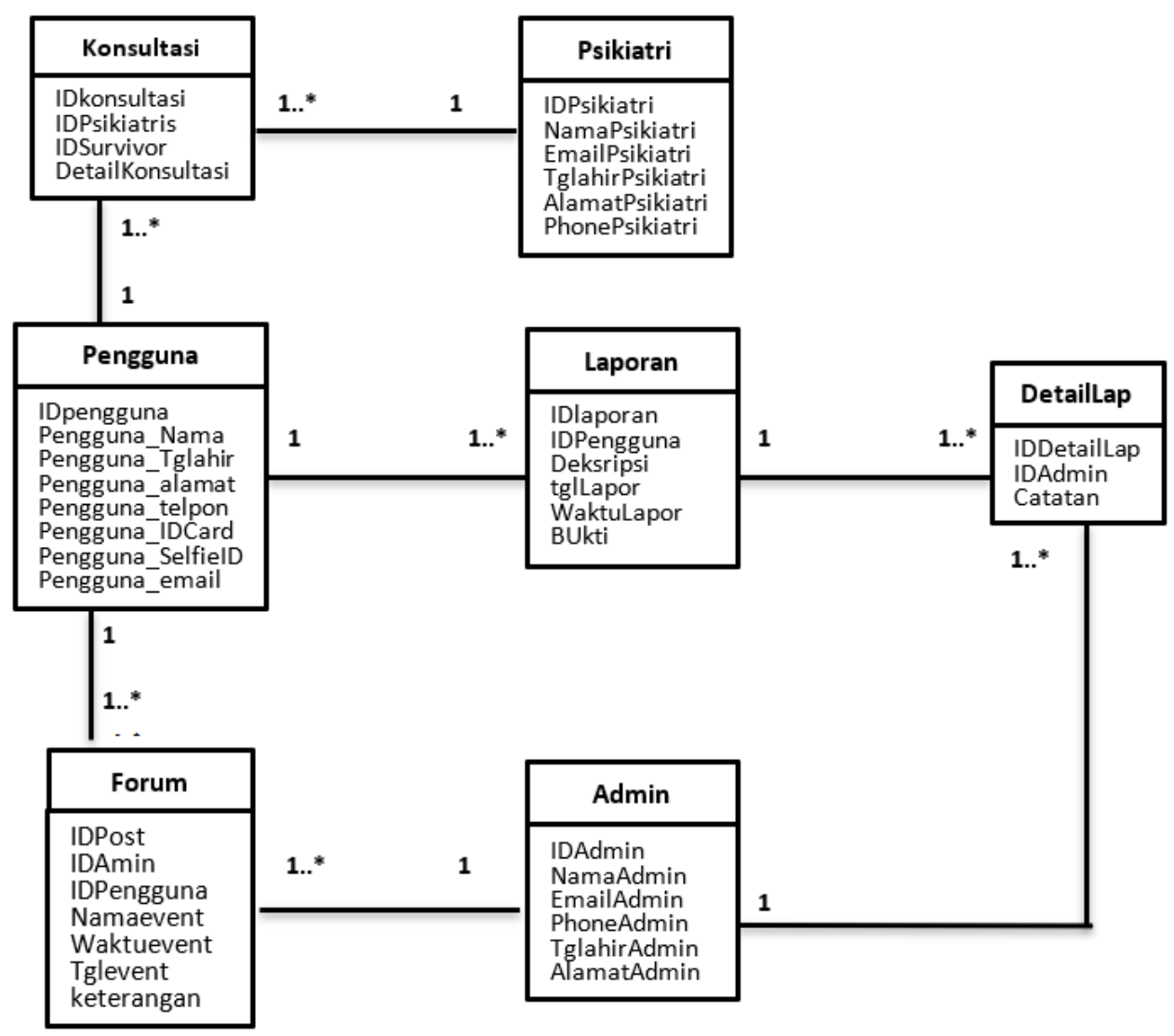

Gambar 2. Class Diagram model desain database untuk aplikasi anti-bully

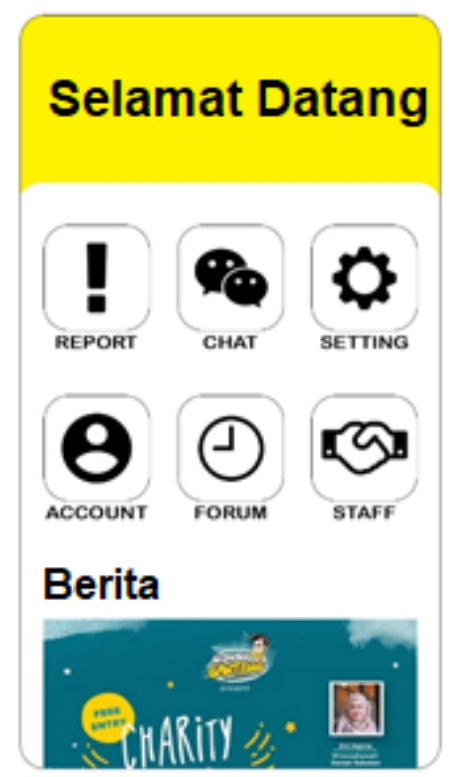

Gambar 3. Menu utama aplikasi

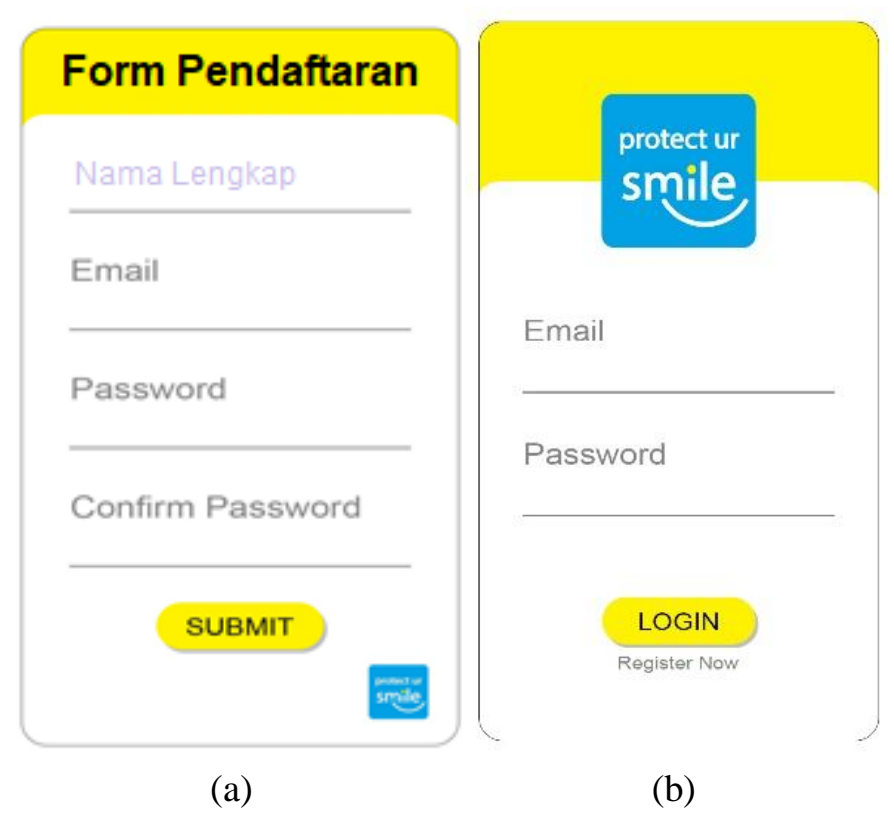

Gambar 4. (a) Menu pendaftaran, (b) Menu masuk systems 

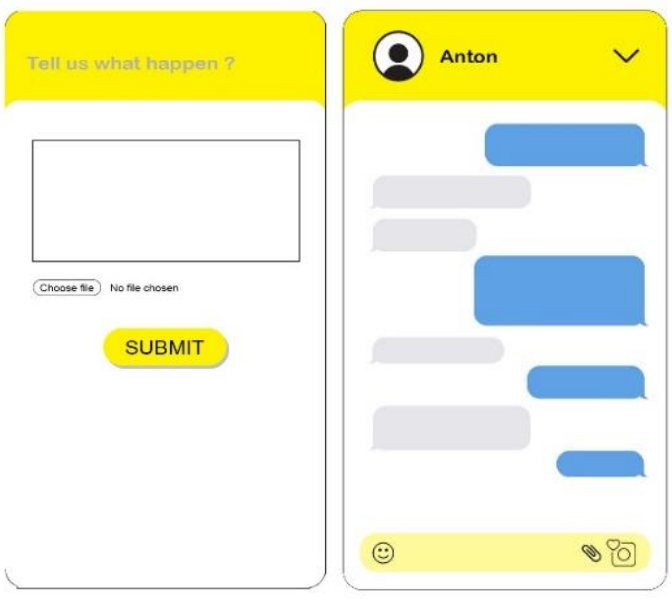

(b)

Gambar 5. (a) Menu Membuat Laporan Bully, (b) Menu Konsultasi

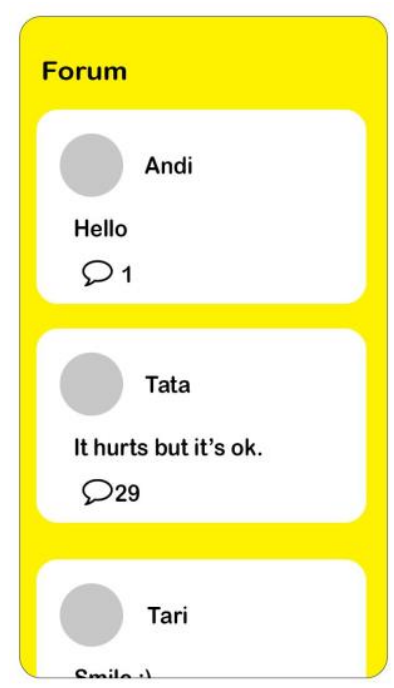

Gambar 6. Menu forum percakapan

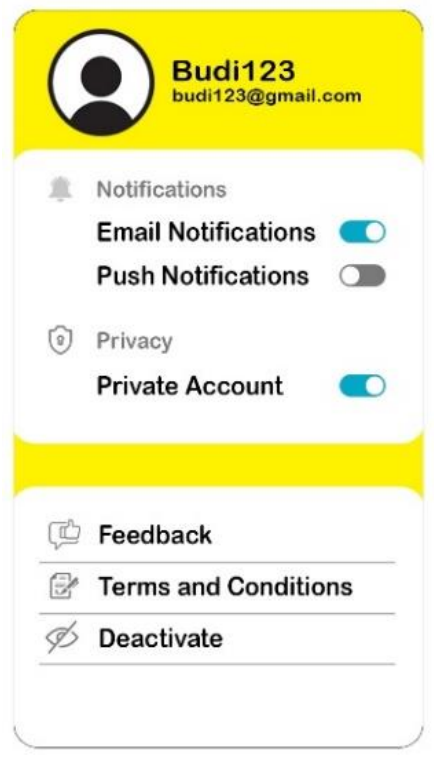

(a)

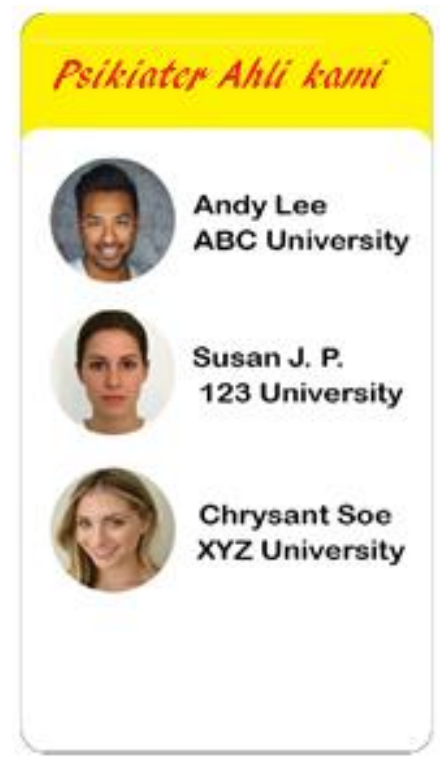

(b)

Gambar 7. (a) Menu Profil pengguna, (b) Menu Profil psikiater

\section{KESIMPULAN DAN SARAN}

Aplikasi ini bertujuan agar survivor tidak hanya terbantu dengan laporan ke polisi tapi juga berkonsultasi dengan psikiater dan berbagi pengalaman dengan orang lain, selain itu komunitas yang terlibat dan peduli dengan bullying dan permasalahannya dapat terbantu dengan aplikasi ini sehingga dapat mengurangi pelaku dan korban bullying, sehingga sesame manusia bisa saling menghargai dan terbentuklah akhlak bangsa Indonesia yang sesuai dengan norma-norma dasar negara kita yaitu Pancasila.

Di masa depan, ada beberapa hal yang dapat ditingkatkan dan dikembangkan di aplikasi ini antara lain dengan menambah lebih banyak fitur, contohnya kontak darurat dan catatan darurat. Dengan aplikasi ini diharapkan dapat mengurangi tindak bullying dan memberi efek jera kepada para pelaku. Tanpa adanya bullying, masyarakat akan menjadi merasa nyaman dan lebih baik, perkembangan anak tidak akan terganggu dan semua orang tidak merasa terintimidasi. 


\section{DAFTAR PUSTAKA}

[1] I. Anindyaputri, "hellosehat," 15 Agustus 2017. [Online]. Available: https://hellosehat.com/parenting/tips-parenting/jenis-bullying-penindasan-di-sekolah/. [Accessed 17August 2019].

[2] D. Setiawan, "KPA.go.id," 10 januari 2019. [Online]. Available: http://www.kpai.go.id. [Accessed 18July 2019].

[3] S. J. Dewaka, "Fasilitas Meditasi Sebagai Sarana Penyembuhan Gangguan Depresi Dan Kecemasan Pada Remaja Dengan Pendekatan Healing Environment", Gadjah Mada University Bachelor Thesis, 2017.

[4] D. J. Sari, S. A. Ides and L. D. Anggraeni, "Latar Belakang Remaja Melakukan Bullying di Sekolah Menengah Kejuruan (SMK)," Latar Belakang Remaja Melakukan Bullying di Sekolah Menengah Kejuruan (SMK), vol. 5, p. 8, 2017.

[5] P. A. Janitra and D. Prasanti, "Komunikasi Keluarga Dalam Pencegahan Perilaku Bullying Bagi Anak," Komunikasi Keluarga Dalam Pencegahan Perilaku Bullying Bagi Anak, vol. 6, p. 12, 2017.

[6] F. Dehue, C. Bolman, and T. Vollink. "Cyberbullying: Youngsters' Experiences and Parental Perception," CyberPsychology \& Behavior, vol. 11, no. 2, 2008.

[7] T. L. Faiza, "Perbedaan Tingkat Depresi pada Korban Bullying Verbal dan Cyberbullying pada Remaja", University of Muhammadiyah Malang Bachelor Thesis, 2019.

[8] A. C. Baldry, "The impact of direct and indirect bullying on the mental and physical health of Italian youngsters," Aggressive Behaviour, vol. 30, no. 5, pp. 343-355, 2004.

[9] L. Arseneault, L. Bowes, and S. Shakoor, "Bullying victimization in youths and mental health problems: 'Much ado about nothing'?," Psychological Medicine, vol. 40, no. 5, pp. 717-729, 2010.

[10] I. Rivers, V. P. Poteat, N. Noret and N.Ashurst, "Observing bullying at school: The mental health implications of witness status.," School Psychology Quarterly, vol. 24, no. 4, pp. 211223, 2009.

[11] D. Olweus, "Bullying at School: Basic Facts and Effects of a School Based Intervention Program" Journal of Child Psychology and Psychiatry, vol. 35, no. 7, pp. 1171-1190, 1994.

[12] P. R. Smokowski and K. H. Kopasz, "Bullying in School: An Overview of Types, Effects, Family Characteristics, and Intervention Strategies," Children \& Schools, vol. 27, no. 2, p. 101-110, 2005.

[13] D. Wolke and S. T. Lereya, " Long-term effects of bullying," Archives of Disease in Childhood, vol. 100, no. 9, pp. 879-885, 2015.

[14] J. Wang, R. J. Iannotti and T. R. Nansel. "School Bullying Among Adolescents in the United States: Physical, Verbal, Relational, and Cyber," Journal of Adolescent Health, vol. 45, no. 4, pp. 368-375, 2009.

[15] P. W. Agatston, R. Kowalski and S. Limber, "Students' Perspectives on Cyber Bullying," Journal of Adolescent Health, vol. 41, no. 6, pp. S59-S60, 2007.

[16] M. M. Ttofi and D. P. Farrington. "Effectiveness of school-based programs to reduce bullying: a systematic and meta-analytic review," Journal of Experimental Criminology, vol. 7, no. 1, pp. 27-56, 2011.

[17] S. M. Swearer and S. Hymel, " Understanding the psychology of bullying: Moving toward a social-ecological diathesis-stress model," American Psychologist, vol. 70, no. 4, pp. 344$353,2015$. 
[18] H. Andershed, M. Kerr and H. Stattin, "Bullying in School and Violence on the Streets: Are the Same People Involved?," Journal of Scandinavian Studies in Criminology and Crime Prevention, vol. 2, no. 1, pp. 31-49, 2010.

[19] M. K. Holt and D. L. Espelage, "Perceived Social Support among Bullies, Victims, and Bully-Victims," Journal of Youth and Adolescence, vol. 36, no. 8, p. 984-994, 2007.

[20] L. Hidayati, "Pembulian di Tempat Kerja dalam konteks Asia" Research Report of Seminar Nasional dan Gelar Produk (SENASPRO), pp. 133-142, 2016.

[21] D. L. Hoff and S. N. Mitchell, "Cyberbullying: causes, effects, and remedies," Journal of Educational Administration, vol. 47, no. 5, pp. 652-665, 2009.

[22] D. Olweus and S. P. Limber, "Bullying in school: Evaluation and dissemination of the Olweus Bullying Prevention Program," American Journal of Orthopsychiatry, vol. 80, no. 1, pp. 124-134, 2010.

[23] T. J. A. Pramesti, "Jerat Hukum Pelaku Bullying Terhadap Anak," =, 4 April 2017. [Online]. Available: https://www.hukumonline.com/klinik/detail/ulasan/lt550264153eb3a/jerathukum-pelaku-ibullying-i-terhadap-anak. [Accessed 7 June 2019]. 